\title{
Testicular seminoma in a dog and its clinical, ultrasonographic, cytological and histopathological aspects: case report
}

\author{
Amanda Bricio Pereira de Andrade 1*, Juliana Gomes Vasconcelos 1, Julia Carrah Colares 1, Francisco \\ Felipe de Magalhães 4 \\ ${ }^{1}$ Faculdade de Veterinária, Universidade Estadual do Ceará, Ceará, CE, Brazil. \\ *Corresponding author: Amanda Bricio Pereira de Andrade. Avenida Barracuda, 610 - Aquiraz. Zip Code: 61700- \\ 000- Ceará, CE, Brazil. Phone: +55 (85) 9 98552-2175. E-mail: mv.amandaandrade@gmail.com.
}

Research Ethics Committee Approval (if necessary): Not applied.

Received on: Jul 11, 2021. Accepted on: Jul 29, 2021. Available online: Aug 4, 2021.

\begin{abstract}
Neoplasms are amongst the main death causes in dogs, with the testis as the second most affected tissue in non-neutered male dogs and seminoma as one of the most common type. In this study, a 12-years-old non-neutered male teckel dog was attended with no perceived clinic. The ultrasound examination revealed a hypoechogenic nodule of ellipsoid shape and slightly heterogeneous echotexture in right testis. The animal was referred for bilateral orchiectomy and histopathological evaluation confirmed the presence of diffuse seminoma in the right testicle and testicular degeneration in both testes. Prognostic factors evaluated in histopathology designated resolution with orchiectomy.
\end{abstract}

Keywords: Canis familiaris; Neoplasms; Andrology; Testis; Diagnostic Imaging.

\section{Introduction}

Neoplasms are amongst the main death causes in dogs and cats, with the testis as the second most affected tissue in non-neutered male dogs [1-2]. Among testicular neoplasms, seminoma is one of the three most common, mainly affecting dogs around 10 years old and being characterized by smooth, softened and white-colored nodules, measuring between 1 and $10 \mathrm{~cm}$ in diameter.

\section{Canine}

seminoma

is predominantly a neoplasm of benign behavior even in cases of malignant histological appearance. The malignancy incidence of this tumor is between $5 \%$ and $10 \%[1,3]$. Cases of metastases have been described in spermatic cord, rede testis, sublumbar lymph nodes, abdominal and thoracic viscera, skin, bone, soft palate, base of the tongue, lip, eye and brain [4-8]. 
Testicular seminoma in a dog and its clinical, ultrasonographic, cytological and histopathological aspects: case report

\begin{tabular}{lll}
\hline \hline Clinical diagnosis is usually & biochemical and cardiac exams \\
made through testicular palpation or & presented no alterations and \\
routine exams [9]. Ultrasonography is & radiographic imaging showed normality \\
the most suitable imaging method for & on chest and spine.
\end{tabular}
initial identification of these tumors. Furthermore, fine needle punctures are used in order to differentiate between neoplastic and inflammatory processes [10]. Nevertheless, the histopathological exam can be performed only after orchiectomy, in order to confirm the neoplastic type and evaluate its prognosis and adequate treatment [9]. In cases such as canine seminomas, the neoplasm is rarely metastatic and is generally not hormone-producing, with the most common incidental ultrasound finding $[2-3,13]$.

Due to the great relevance of testicular diseases in the companion animal clinics routine, it is essential to obtain detailed and updated information aiming to assist accurate and efficient diagnoses and treatments for such conditions. Therefore, this study aims to report clinical, ultrasound, cytological and histopathological aspects of seminoma in a canine male Teckel assisted in a public veterinary hospital in the state of Ceará.

\section{Case report}

A 12-years-old non-neutered male teckel dog was attended at the Veterinary Hospital Sylvio Barbosa Cardoso of the State University of Ceará. The patient was brought for periodic examinations, with no perceived clinic. Hematological,

The ultrasound examination was performed in a Logiq F6 ultrasound (GE Healthcare, USA) with linear transducer at frequency of $8.0 \mathrm{MHz}$. A hypoechogenic nodule of ellipsoid shape and slightly heterogeneous echotexture was visible in right testis, with dimensions of $1.25 \mathrm{~cm}$ in height and $1.45 \mathrm{~cm}$ in length (Figure 1B).

Despite the nodule, testicular dimensions were maintained. In left testicle parenchyma, a slight echotexture alteration was perceived (Figure 1A). No metastatic-like or lymph node changes were visible during the abdominal ultrasound evaluation. Due to the suspicion of unilateral testicular neoplasia, the animal was referred for bilateral orchiectomy. The right testicle was directed to cytological evaluation of the nodule and both testes were directed to histopathologic exams.

The patient presented no postsurgical complications and 10-day posterior clinical attendance showed no clinical alterations, healed surgical incision and scrotum with no infections, inflammations or pain on palpation.

Cytology of the right testicle was performed at operating room, using fine needle puncture. In cytological sample (Figure 1D), moderate individualized epithelial cellularity was found, presenting marked anisocytosis, moderately basophilic cytoplasm and 
Testicular seminoma in a dog and its clinical, ultrasonographic, cytological and histopathological aspects: case report

\begin{tabular}{|c|c|}
\hline $\begin{array}{l}\text { high nucleus:cytoplasm ratio. The nuclei } \\
\text { were occasionally eccentric, the } \\
\text { chromatin was coarse and the nucleoli } \\
\text { were evident and varying in quantity }\end{array}$ & 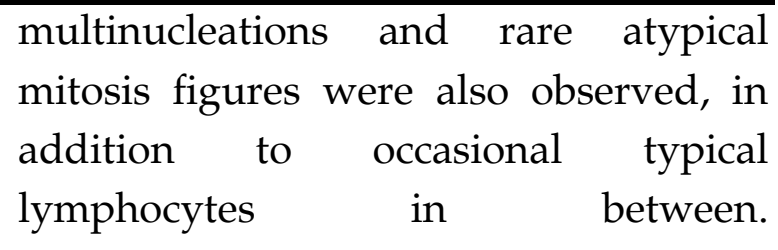 \\
\hline
\end{tabular}
and size. The presence of binucleations,

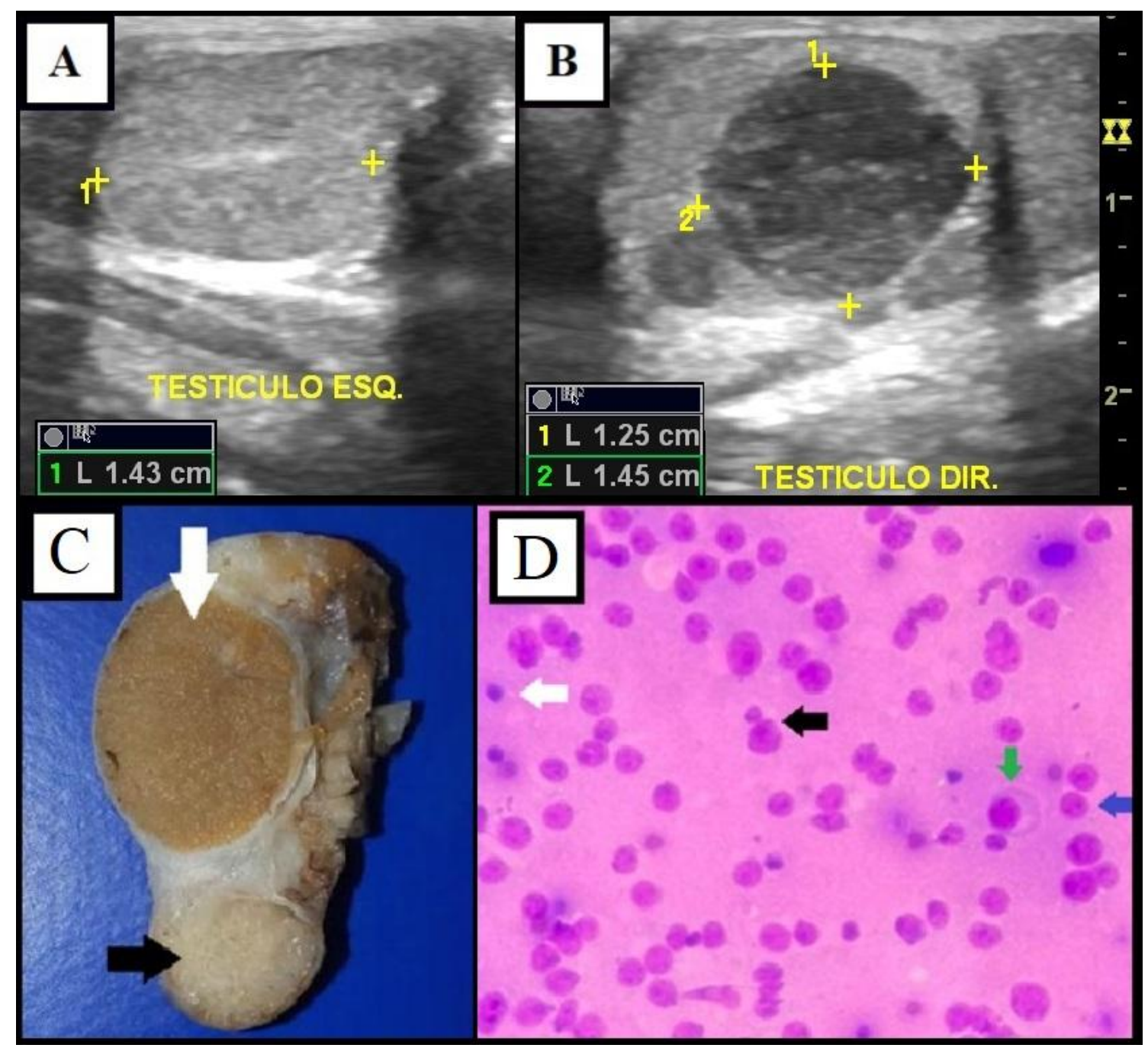

Figure 1. A. Ultrasonographic image of left testis. Longitudinal section, with slightly heterogeneous echotexture, compatible with patient's age. B. Ultrasound image of right testis. Longitudinal section, presenting a hypoechogenic nodule of slightly heterogeneous echotexture and measuring $1.25 \mathrm{~cm}$ in height and $1.45 \mathrm{~cm}$ in length. $\mathbf{C}$. Macroscopic image of right testes, presenting a compact white nodule (white arrow) and dilated epididymis (black arrow). D. Cytology of right testis, presenting epithelial cellularity, lymphocytic infiltrate (white arrow), presence of multinucleations (blue arrow), eccentric nuclei (green arrow) and marked anisocytosis (black arrow). 
Testicular seminoma in a dog and its clinical, ultrasonographic, cytological and histopathological aspects: case report

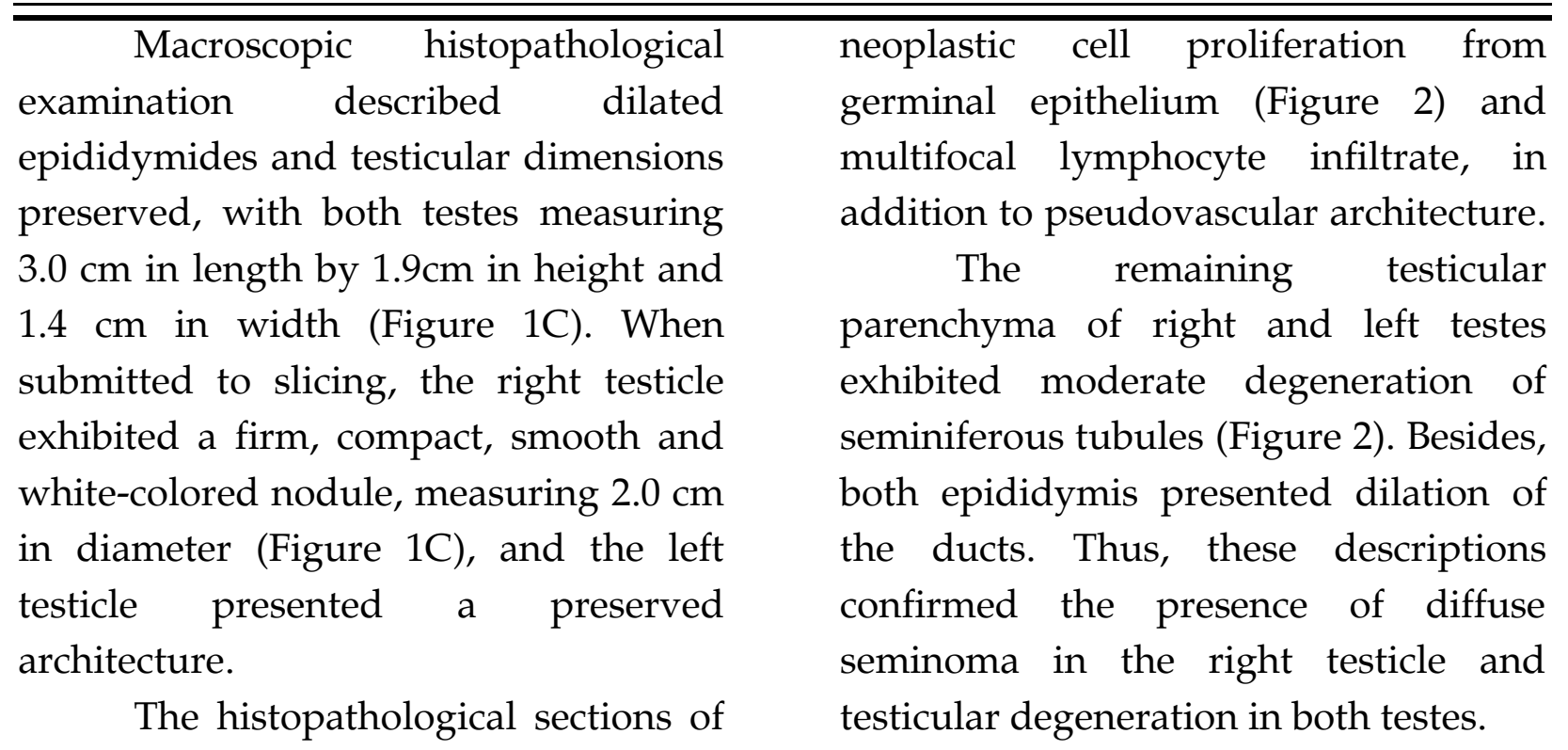

the nodule showed well-defined diffuse

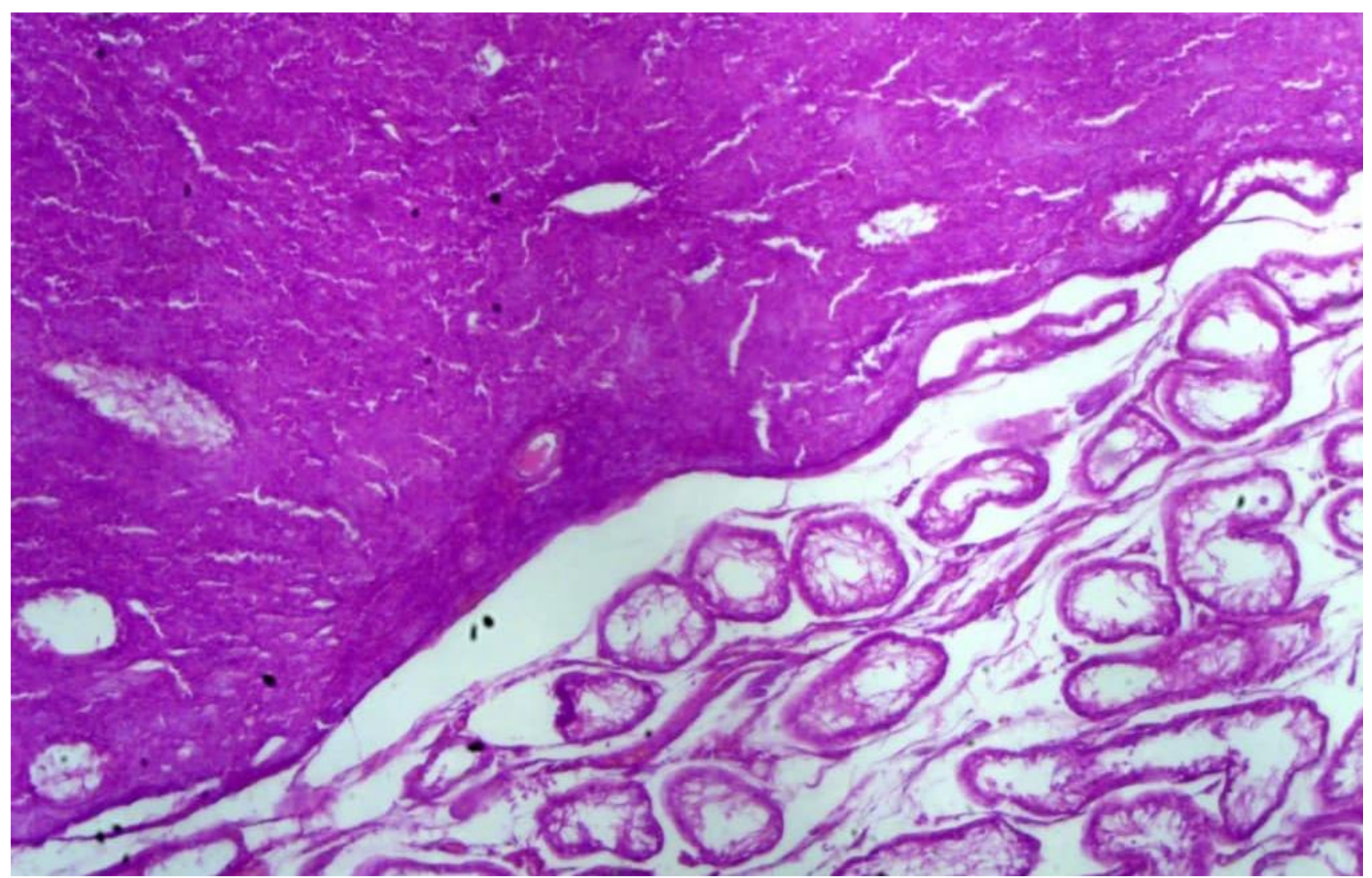

Figure 2. Histopathologic sections of the right testis with neoplastic cell proliferation from germinal epithelium (left and superior) and remaining testicular parenchyma with moderate degeneration of seminiferous tubules (right an inferior).

The prognostic factors evaluated in histopathology designate a resolution with bilateral orchiectomy, given that there was no vascular or perineural neoplastic invasion and the lateral and deep surgical margins were free of neoplastic aspects. Thus, none adjacent 
Testicular seminoma in a dog and its clinical, ultrasonographic, cytological and histopathological aspects: case report

treatments, such as chemotherapy, was performed.

\section{Discussion and Conclusion}

This patient was of Teckel-breed, a breed with no definite predisposition for testicular neoplasms [2], however his advanced age fits him in a predisposed condition. Both testicles were presented in adequate topography, thus, there was no cryptorchidism, a factor that commonly leads to testicle neoplasms development [1-2]. Recent reports of seminoma in non-cryptorchid animals described mixed testicular neoplasms and/or metastases [4-6], which was not the case for this animal.

Only one report in literature describes a non-metastatic and unmixed seminoma in a non-ectopic testis, identified due to testicular enlargement [11], one of the first characteristic symptoms of these neoplasms. However, the case reported in this essay is the first to describe a benign isolated seminoma in an asymptomatic animal, as is most frequent in dogs [2].

In addition to absent of clinical signs, hematological and biochemical laboratory tests and chest radiography also presented no alterations. Normality of these exams has been described in other case of isolated seminoma in nonectopic testes [11]. In general, such exams demonstrate changes in cases of metastases or paraneoplastic syndromes, having great importance for clinical and prognostic evaluation in cases of malignancy [2].
The ultrasound changes reported are in accordance with the described in literature for testicular neoplasms, whose present variable and non-specific aspect [3]. Ultrasonography was the only performed exam that allowed the identification of the nodule, reinforcing its importance in routine geriatric evaluations. As previously described, ultrasound allows the differentiation between tumor processes and other conditions such as orchitis, epididymitis and testicular torsion, being sufficient for surgical indication for both neoplastic or not-neoplastic tumors [2].

Bilateral orchiectomy is the treatment of choice for cases of testicular neoplasms. Fifty percent of dogs diagnosed with seminoma are affected bilaterally, but only $12 \%$ are detected in the contralateral testis [2]. For this reason, bilateral orchiectomy was performed in this case shortly after ultrasound indication, although changes were found only in right testis.

After slicing, the right testis presented a nodule compatible with the described in literature for seminoma [13]. Its dimension of $2 \mathrm{~cm}$ in diameter did not affect the testicular size in clinical or ultrasound evaluation, thus only compressed the parenchyma. The white coloration is described in seminomas and sertoliomas. Nevertheless, the smooth, non-nodulated structure is similar to the description of seminomas, while the firm consistency is more found in sertoliomas [2]. Thus, despite the relative macroscopic distinction 
Testicular seminoma in a dog and its clinical, ultrasonographic, cytological and histopathological aspects: case report

between the main testicular tumors, only with microscopic assessment of histopathology is it possible to certify the tumor type [2].

Cytology has a $95 \%$ sensitivity for canine seminomas and the aspects described as basophilic cytoplasm, large nuclei, coarse chromatin and atypical mitoses are commonly found in this type of tumor. Despite the presence of major nuclear changes, the behavior of seminomas often remains without traces of malignancy [12]. Multifocal lymphocytic infiltrates were found in both cytology and histopathology, being common in several tumor types [2], but characteristic of seminoma [12]. Considering the most common neoplastic types in canine testis, the proliferation of epithelial tissue and the characteristics described in literature, cytology suggests the presence of seminoma. In addition, both other most common testicular neoplasms are of stromal cell proliferations, these being leydigocytoma and sertolioma [1].

The histopathological sections allowed the tumor type specification when visualizing cellular neoplastic proliferation of germinal epithelium, confirming the presence of seminoma in right testis. The neoplastic distribution was assessed as diffuse, being a type of seminoma in which cell proliferation is not limited to seminiferous tubules. Cell proliferation of this type are organized in "wide sheets" among testicular parenchyma and are considered by some authors as the evolution of intratubular seminoma, with greater potential for malignancy. Nevertheless, prognostic aspects evaluated in histology indicated benign neoplastic behavior, since proliferation was well defined and without signs of adjacent tumor infiltration or metastases [1, 2]. In cases such as canine seminomas, the neoplasm is rarely metastatic and generally not hormone-producing $[2,3$, 13].

Parenchyma evaluation of both testis indicated degeneration of seminiferous tubules. A previous study evaluating canine testicular disorders described that all cases of unilateral neoplasms had some degree of degeneration in contralateral testis [13], reinforcing the relationship between seminoma and testicular degeneration found in this case report.

Whereas, no metastatic alterations were found in ultrasound evaluation and prognostic factors evaluated in histopathology presented margins free of neoplasia, the surgery itself was sufficient for the resolution of this case. Thus, there was no need for adjacent treatments such as chemotherapy.

This case report exemplifies that, although the left testis does not present any clinical or ultrasound alteration, its removal was of great importance to avoid future problems due to the already existing testicular degeneration. Bilateral orchiectomy is, therefore, the ideal and already established resolution in literature for cases of canine testicular 
Testicular seminoma in a dog and its clinical, ultrasonographic, cytological and histopathological aspects: case report

neoplasms [2] due to the possibilities of having an undetectable neoplasm or non-neoplastic degeneration in contralateral testis.

Additionally, this case reinforces the importance of routine examinations in geriatric animals, not only abdominal, but also gonadal. The condition described was accidentally found only by ultrasound evaluation, as the animal did not present clinic symptoms. The early diagnostic by the image exam also leads to a favorable prognosis for these affections. Thus, the case was an example of an ideal conclusion for the patient's health, ending all present reproductive disorders through bilateral orchiectomy.

\section{References}

[1] Agnew DW, MacLachlan NJ Tumors of the Genital Systems. In: Meuten DJ (Ed.). Tumors in domestic animals. 5.ed. Ames: John Wiley \& Sons, p.689-722, 2017.

[2] Lawrence JA, Saba CF. Tumors of the Male Reproductive System. In: Knapp DW, SK M (Eds). Withrow and MacEwen's Small Animal Clinical Oncology. 6.ed. St. Louis: W.B. Saunders, p.557-571, 2019.

[3] Carvalho CF, Guido MC, Tannouz VGS. Aparelho Reprodutor Masculino. In: Carvalho CF Ultrassonografia em pequenos animais. 2.ed. São Paulo: Roca, p.283-297, 2014.

[4] Dias SL, Moroz LR, Souza DFRP, Simões LO, Peixoto TC, Pires CG.
Metástase de seminoma em região orbital em cão-relato de caso. Arquivo Brasileiro de Medicina Veterinária e Zootecnia. 2020; 72(2):332-338. http:/ / doi.org/10.1590/1678-416210179.

[5] Lucas X, Rodenas C, Cuello C, Gil MA, Parrilla I, Soler M, Belda E, Agut A. Unusual systemic metastases of malignant seminoma in a dog. Reproduction in domestic animals. 2012;47(4):59-61. https: //doi.org / 10.1111/ j.14390531.2011.01927.x.

[6] Takiguchi $M$, Iida $T$, Kudo $T$, Hashimoto A. Malignant seminoma with systemic metastases in a dog. Journal of Small Animal Practice. 2001;4(7):360-362. https:// doi.org/ 10.1111/j.1748-5827.2001.tb02475.x

[7] HogenEsch H, Whiteley HE, Vicini DS, Helper LC. Seminoma with metastases in the eyes and the brain in a dog. Veterinary pathology. 1987;24(3):278-280. https:// doi.org/ $10.1177 / 030098588702400315$.

[8] Dugat DR, Medici EL, Rochat MC, Arble JA, Snider TA. An unusual case of metastatic seminoma in a dog. Journal of the American Animal Hospital Association. 2015;51(6):401-406. https: / / doi.org/10.5326/JAAHA-MS6263.

[9] Feldman EC, Nelson RW. Disorders of the Testes and Epidymides. In: Feldman EC, Nelson RW (Eds). Canine and Feline Endocrinology and 
Testicular seminoma in a dog and its clinical, ultrasonographic, cytological and histopathological aspects: case report

\begin{abstract}
Reproduction. 3.ed. St. Louis: W.B. Saunders Co, p.961-977, 2004.

[10] Domingos TCS, Salomão MC Meios de diagnóstico das principais afecções testiculares em cães: revisão de literatura. Revista Brasileira de Reprodução Animal. 2011;35(4):393-399.

[11] Ciaputa R, Nowak M, Kielbowicz M, Antonczyk A, Blasiak K, Madej JA. Seminoma, sertolioma, and leydigoma in dogs: clinical and morphological correlations. Bulletin of the Veterinary Institute in Pulawy. 2012;56(3):361-367. https:/ /doi.org/10.1590/1678-416210179.

[12] Masserdotti C, Bonfanti U, Lorenzi D, Tranquillo M, Zanetti O. Cytologic features of testicular tumours in dog. Journal of Veterinary Medicine Series A. 2005;52(7):339-346. https: // doi.org/ 10.1111 /j.1439-0442.2005.00735.x.
\end{abstract} report. Brazilian Journal of Case Reports. 2021 Jul-Sep; 01(3):66-73.

[13] Câmara LBRM, Câmara DR, Maiorino FC, Silva Jr.V, Guerra MMP. Canine testicular disorders and their influence on sperm morphology. Animal Reproduction. 2018;11(1):32-36.

Conflict of interest: The author declares no conflicts of interest.

Acknowledgements: None.

Funding: None.

How to cite this article: Andrade ABP, Vasconcelos JG, Colares JC, Magalhães FF. Testicular seminoma in a dog and its clinical, ultrasonographic, cytological and histopathological aspects: case 